\title{
Mild Cognitive Impairment - A Preclinical State of Alzheimer's Disease?
}

\author{
a report by \\ Wolf-Dieter Heiss, Cathleen Hänse and Kerholz
}

\author{
Max Planck Institute for Neurological Research Cologne, Germany and \\ Wolfson Molecular Imaging Centre, Manchester, England
}

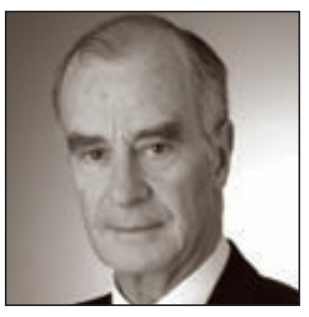

Wolf-Dieter Heiss is President of the European Federation of Neurological Societies (EFNS), Professor and Chairman in the University of Neurology at the University of Cologne and Director at the Max Planck Institute for Neurological Research in Cologne.

He has won numerous awards including the Zulch Prize in 1994, the Mihara Award in 1995, the Bergmann-Plakette prize in 1999 and the Berson-Yalow Award in 2002. He is a member of the American Neurological Association, the Stroke Council of the American Heart Association, the Society of Nuclear Medicine, the Société Française de Neurologie and the International Stroke Society (President 1992-1996), among others.

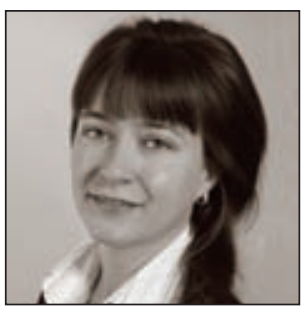

Cathleen Hänse is a post-doctoral research fellow at the Max Planck Institute for Neurological Research, Cologne, with research interests focusing on neuroimaging (particularly positron emission tomography (PET)) in neurological and psychiatric diseases and PET, neuropsychology and

pharmacological/genetic bases of ageing and dementia.
With a prevalence of 4,886,252 cases, dementia is one of the leading brain disorders in the European Community and is responsible for estimated total costs of $€ 55$ billion. ${ }^{1}$ The prevalence of dementia is dependent on the age group with a mean of 2.1 cases/100 of the population in the group 65-74 years, of $6.9 / 100$ in the group $75-84$ years and $27 / 100$ in the group beyond 84 years. ${ }^{2}$

A considerable larger population suffers from a transition phase between healthy cognitive ageing and dementia for which several definitions and names were coined: ${ }^{3}$ benign senescent forgetfulness, ${ }^{4}$ ageassociated memory impairment (AAMI), ${ }^{5}$ late-life forgetfulness, ${ }^{6}$ ageing-associated cognitive decline, ${ }^{7}$ cognitive impairment - no dementia $(\mathrm{CIND})^{8}$ and mild cognitive impairment (MCI). ${ }^{9}$

Some of these definitions also were introduced into Diagnostic and Statistical Manual of Mental Disorders IV (DSM IV) (American Psychiatric Association 1994) and International Classification of Diseases (ICD). ${ }^{10}$

The prevalence of these conditions is dependent on the definition resulting in large differences, ranging from $20 \%$ for $\mathrm{AAMI}^{10}$ and $16.8 \%$ for $\mathrm{CIND}^{8}$ to $3 \%$ for $\mathrm{MCI}^{9}$ of the population studied. First, the concept of MCI defined by Petersen et al. in 1997 was restricted to only memory impairment and leads to the identification of people at a high risk of progression to Alzheimer's disease. ${ }^{11}$

Due to the heterogeneity of the clinical presentation and the different neuropsychological profiles as well as the clinical course and outcome of numerous MCI subjects (some patients will regain normal cognitive function, some will remain stable and some will show a progression of symptoms to different types of dementia) Petersen extended the primarily concept to a syndrome-type classification: ${ }^{12}$

- amnestic MCI which is characterised by the following criteria;

- memory complaint, preferably corroborated by an informant and/ or by the subjects themselves;

- objective impaired memory function relative for age and education;

- preserved general cognitive function;

- intact basic activities of daily living; and

- no dementia.

This subtype preferentially progresses to Alzheimer's disease $^{13}$ and therefore this definition will be used in the present review.

- multiple domain MCI - slightly impaired (characterised by a slight impairment of multiple cognitive domains); and

- single-domain non-memory MCI (isolated impairment of a cognitive domain other than of memory).

By definition, all these concerned persons are not demented, but a considerable percentage progresses to dementia (10-15\% per year). ${ }^{13}$

Even within the restrictive definition of (amnestic) MCI, there exists considerable aetiological heterogeneity among individuals which is also responsible for the variable prognosis and the different probability to convert into Alzheimer dementia (AD) or vascular cognitive impairment. ${ }^{3,14}$

\section{Diagnosis of $\mathrm{MCI}$}

The various syndromes of mild cognitive impairment in the broader sense have different operational definitions, ${ }^{14}$ and have different prognoses for progression to dementia. Since amnestic mild cognitive impairment as defined by Petersen et al. ${ }^{9}$ has a high conversion rate to Alzheimer dementia, its diagnosis and the differentiation from both normal cognitive ageing and incipient dementia disease is of great importance.

Specific recommendations for criteria of MCI were formulated, including evidence of cognitive deterioration shown over time and measured objectively. ${ }^{15}$ For the objective measurement of this decline standard neuropsychological tests are applied in which poor performance on delayed recall and 
executive functions indicate a high risk for progression to $\mathrm{AD} \cdot{ }^{16,17}$

These tests are complimentary to the mini-mental state examination, which has been found to be insensitive to MCI and is often within the normal range in most patients with MCI. Supplementary information from a knowledgeable informant (e.g. a family member) concerning the individual's memory abilities can be particularly also helpful as some patients may be unaware of their cognitive changes. ${ }^{18}$ Additional to the cognitive impairment most patients with MCI suffer from behavioural and psychological symptoms as anxiety, depression, irritability and apathy.

These complaints often make the correct diagnosis difficult, but they may suggest other disorders, as frontotemporal dementia, Lewy body dementia or vascular origin of cognitive impairment. Despite the operational definitions and the broad neuropsychological testing difficulties remain in defining the boundaries between normal ageing and MCI, and between MCI and mild dementia.
The consistent feature of numerous studies points out that increased total tau and phosphotau concentrations are highly sensitive while low $A \beta 42$ levels are more specific. It was interesting to note, however, that there might be an inverse relationship between brain amyloid deposition and A $\beta 42$ concentration in cerebrospinal fluid. ${ }^{26}$

Additionally, assessment of the APOE genotype may allow an early high-risk and low-risk stratification ${ }^{27,28}$ with a greater deleterious effect of the APOE $\alpha E 4$ genotype on gross hippocampal pathology and memory function in women than in men. ${ }^{29}$

Various biomarkers have been selected for multicentre longitudinal studies of MCI and AD and for therapeutic trials. Regardless of these analyses, there is currently insufficient evidence for the use of blood biomarkers in predicting $\mathrm{AD}$ conversion amongst MCI subjects.

Neuro imaging

Investigations of brain morphology with magnetic

\section{The consistent feature of numerous studies points out that} increased total tau and phosphotau concentrations are highly sensitive.

\section{Biomarkers}

Biomarkers in the cerebrospinal fluid may help to differentiate between MCI and normal ageing and identify those patients at risk for progression to AD. The markers studied so far include total tau, phos-phorylated tau and $\beta$-amyloid 1-42 $(\mathrm{A} \beta 42),{ }^{19,20}$ which all have properties for classification and early diagnosis. Phosphotau can especially increase the diagnostic accuracy of conventional cognitive and imaging assessment in subjects with MCI. ${ }^{21}$ Longitudinal hippocampal volume losses in these patients are closely associated with increasing hyperphos-phorylated tau. ${ }^{22}$ In follow-up studies of MCI patients concentrations of these markers were strongly associated with further development of AD. ${ }^{23}$

The most predictive assay for AD among the patients with MCI seems to be the combination of $A \beta 42$ and phophotau ${ }^{24}$ and accordingly the combination of high total tau/ phosphotau and low A $\beta 42$ concentrations. ${ }^{25}$ resonance imaging (MRI) have demonstrated medial temporal lobe atrophy in people with MCI compound with cognitively normal individual ${ }^{30,31}$ and this atrophy is predictive of progression to dementia. ${ }^{32,33}$ The variability of volumetric determinations of brain atrophy is rather high, and thresholds of abnormality are difficult to define. Therefore, functional measures were used additionally. Quantitative topographical electroencephalography can improve the diagnostic accuracy in dementias ${ }^{34}$ and $\mathrm{MCI}^{35}$, but these approaches suffer from high variability and restricted spatial resolution.

An additional special diagnostic tool in predicting conversion to probable AD can be the N-acetylaspartate/ creatinine ratio in the occipital cortex using proton magnetic resonance spectroscopy (1H-MRS). ${ }^{36}$

Positron emission tomography (PET) permits to measure quantitatively energy metabolism, blood flow, concentration of transmitters and receptors, amino-acid transport, and accumulation of ligands to abnormal proteins with high spatial resolution and 
was extensively applied to the study of various dementias and of cognitive impairment in ageing. Based on a large number of studies of regional glucose consumption with ${ }^{18}$ Fluor-deoxyglucose and PET, ${ }^{37}$ a multicentre study within the European Community defined discrimination thresholds between normals and $\mathrm{AD}$ patients which can be obtained in an automatic analysis of regional values of cerebral metabolic rate for glucose $\left(\mathrm{CMR}_{\mathrm{Glc}}\right) \cdot{ }^{38}$ The calculated $\mathrm{T}$-sums of reduction in regional $\mathrm{CMR}_{\mathrm{Glc}}$ are closely correlated to the score in minimental state examination (MMSE) and permit a reliable differentiation of patients from normal age matched controls.
In a preliminary study in eight subjects with MCI four patients showed significant decrease in cortical AChE activity; all of them converted to $\mathrm{AD}$ within the observation period of 18 months, whereas the 4 individuals with normal cortical AChE activity did not deteriorate. ${ }^{46}$ Another promising tracers for detection of deposition of amyloid - the hallmarks of AD - are ${ }^{11} \mathrm{C}-$ labelled arylbenzothiazoles, known as Pittsburgh Compound-B. ${ }^{47}$ In cortical areas PIB retention was increased in AD and correlated inversely with cerebral glucose metabolism. ${ }^{48,49}$ As cerebrospinal fluid $A \beta 42$ concentration is inversely related to amyloid deposition, it might be hypothesised that amyloid plaques act as a risk of $A \beta 42 .^{26}$

\section{Recent studies suggest that PIB-amyloid imaging may be sensitive for detection of preclinical AD states.}

Changes of regional CMRGlc were also found in many subjects with $\mathrm{MCI}$ and these changes were predictive of clinical progression to Alzheimer disease within a follow-up period of more than a year. ${ }^{30,39-44}$ These reduction of $\mathrm{CMR}_{\mathrm{Glc}}$ in $\mathrm{AD}$ typical brain regions were related to elevated phosphor-tau levels ${ }^{21}$ and combined to assessment of the APOE genotype improved identification of high-risk patients. ${ }^{28}$ Acetylcholine esterase activity as a marker of cholinergic activity is reduced in AD. ${ }^{45}$ The cholinergic system is important for memory functions, and therefore the decrease in AChE activity might be a predictor of conversion from MCI to $\mathrm{AD}$.
Recent studies suggest that PIB-amyloid imaging may be sensitive for detection of preclinical AD states, ${ }^{50,51}$ but additional longitudinal studies are required to prove this hypothesis.

These new imaging and CSF tests are very promising for the prediction of prognosis which otherwise is uncertain for patients with a clinical diagnosis of MCI. The identification of MCI subjects with high risk of short term progression to AD might be essential for the development of treatment strategies to prevent or delay clinical deterioration, ${ }^{52}$ which have up to now not been successful. ${ }^{53}$

\section{References}

1. Andlin-Sobocki P, Jonsson B, Wittchen HU, Olesen J, "Cost of disorders of the brain in Europe", Eur J Neurol (2005);12(6) Suppl 1: pp. 1-27.

2. Jonsson L, Berr C, "Cost of dementia in Europe", Eur J Neurol (2005);June;12 Suppl 1: pp. 50-53.

3. Decarli C, "Mild cognitive impairment: prevalence, prognosis, aetiology, and treatment" Lancet Neurology (2003);2: pp. 15-21.

4. Kral VA, "Senescent forgetfulness: benign and malignant" Can Med Assoc J (1962);February 10;86: pp. 257-60.

5. Crook T, Bartus R, Ferries Seal, "Age-associated memory impairment: Proposed diagnostic criteria and measures of change”, Dev Neuropsychol (1986);2: pp. 261-276.

6. Blackford RC, La Rue A, "Criteria for diagnosing age associated memory impairment: proposed improvements in the field", Dev Neuropsychol (1989); 5: pp. 295-306.

7. Levy R, "Aging-associated cognitive decline. Working Party of the International Psychogeriatric Association in collaboration with the World Health Organization", Int Psychogeriatr (1994);6(1): pp. 63-68.

8. Graham JE, Rockwood K, Beattie BL, et al., "Prevalence and severity of cognitive impairment with and without dementia in an elderly population", Lancet (1997);349(9068): pp. 1793-1796.

9. Petersen RC, Smith GE, Waring SC, et al., "Mild cognitive impairment: clinical characterization and outcome", Arch Neurol (1999);56(3): pp. 303-308. 
10. Goldman WP, Morris JC, "Evidence that age-associated memory impairment is not a normal variant of aging", Alzheimer Dis Assoc Disord (2001);15(2): pp. 72-79.

11. Petersen RC, Smith GE, Waring SC, et al., "Aging, memory, and mild cognitive impairment", Int Psychogeriatr (1997);9 Suppl 1: pp. 65-69.

12. Petersen RC, "Mild cognitive impairment as a diagnostic entity", J Intern Med (2004) September;256(3): pp. 183-194.

13. Petersen RC, Doody R, Kurz A, et al., "Current concepts in mild cognitive impairment", Arch Neurol (2001);58(12): pp. 1985-1992.

14. Gauthier S, Reisberg B, Zaudig M, et al., "Mild cognitive impairment”, Lancet (2006);367(9518): pp. 1262-1270.

15. Winblad B, Palmer K, Kivipelto M, et al., "Mild cognitive impairment - beyond controversies, towards a consensus: report of the International Working Group on Mild Cognitive Impairment”, J Intern Med (2004);256(3): pp. 240-246.

16. Chen P, Ratcliff G, Belle SH, et al., "Cognitive tests that best discriminate between presymptomatic AD and those who remain nondemented”, Neurology (2000);55(12): pp. 1847-1853.

17. Artero S, Tierney MC, Touchon J, Ritchie K, "Prediction of transition from cognitive impairment to senile dementia: a prospective, longitudinal study”, Acta Psychiatr Scand (2003);107(5): pp. 390-393.

18. Carr DB, Gray S, Baty J, Morris JC, "The value of informant versus individual's complaints of memory impairment in early dementia”, Neurology (2000);55(11): pp. 1724-1726.

19. Blennow K, Hampel H, “CSF markers for incipient Alzheimer's disease”, Lancet Neurol (2003);2(10):605-13.

20. Andreasen N, Sjogren M, Blennow K, "CSF markers for Alzheimer's disease: total tau, phospho-tau and Abeta42”, World J Biol Psychiatry (2003);4(4): pp. 147-155.

21. Fellgiebel A, Siessmeier T, Scheurich A, et al., "Association of elevated phospho-tan levels with Alzheimer-typical 18Ffluoro-2-deoxy-D-glucose positron emission tomography findings in patients with mild cognitive impairment", Biol Psychiatry (2004);56(4): pp. 279-83.

22. De Leon MJ, Desanti S, Zinkowski R, et al., "Longitudinal CSF and MRI biomarkers improve the diagnosis of mild cognitive impairment”, Neurobiol Aging (2006);27(3): pp.394-401.

23. Hansson $O$, Zetterberg H, Buchhave P, et al., "Association between CSF biomarkers and incipient Alzheimer's disease in patients with mild cognitive impairment: a follow-up study”, Lancet Neurol (2006);5(3): pp. 228-234.

24. Herukka SK, Hallikainen M, Soininen H, Pirttila T, "CSF Abeta42 and tau or phosphorylated tau and prediction of progressive mild cognitive impairment”, Neurology (2005);64(7): pp. 1294-1297.

25. Parnetti L, Lanari A, Silvestrelli G, et al., "Diagnosing prodromal Alzheimer's disease: role of CSF biochemical markers.", Mech Ageing Dev (2006);127(2): pp. 129-132.

26. Fagan AM, Mintun MA, Mach RH, et al., "Inverse relation between in vivo amyloid imaging load and cerebrospinal fluid Abeta42 in humans”, Ann Neurol (2006);59(3): pp. 512-519.

27. Reiman EM, Caselli RJ, Yun LS, et al., "Preclinical evidence of Alzheimer's disease in persons homozygous for the epsilon 4 allele for apolipoprotein E”, N Engl J Med (1996);334(12): pp. 752-758.

28. Drzezga A, Grimmer T, Riemenschneider $M$, et al., "Prediction of individual clinical outcome in MCI by means of genetic assessment and (18)F-FDG PET", J Nucl Med (2005);46(10): pp. 1625-1632.

29. Fleisher A, Grundman M, Jack CR, Jr., et al., "Sex, apolipoprotein E epsilon 4 status, and hippocampal volume in mild cognitive impairment”, Arch Neurol (2005);62(6): pp. 953-957.

30. De SS, De Leon MJ, Rusinek H, et al., "Hippocampal formation glucose metabolism and volume losses in MCI and AD”, Neurobiol Aging (2001);22(4): pp. 529-539.

31. Toledo-Morrell L, Stoub TR, Bulgakova M, et al., "MRI-derived entorhinal volume is a good predictor of conversion from MCI to AD”, Neurobiol Aging (2004);25(9): pp. 1197-1203.

32. Korf ES, Wahlund LO, Visser PJ, Scheltens P, "Medial temporal lobe atrophy on MRI predicts dementia in patients with mild cognitive impairment”, Neurology (2004);63(1): pp. 94-100.

33. Stoub TR, Bulgakova M, Leurgans S, et al., "MRI predictors of risk of incident Alzheimer disease: a longitudinal study", Neurology (2005);64(9): pp. 1520-1524.

34. Szelies B, Grond M, Herholz K, et al., "Quantitative EEG mapping and PET in Alzheimer's disease”, J Neurol Sci (1992);110(1-2): pp. 46-56.

35. Koenig T, Prichep L, Dierks T, et al., "Decreased EEG synchronization in Alzheimer's disease and mild cognitive impairment”, Neurobiol Aging (2005);26(2): pp. 165-171.

36. Modrego PJ, Fayed N, Pina MA, "Conversion from mild cognitive impairment to probable Alzheimer's disease predicted by brain magnetic resonance spectroscopy”, Am J Psychiatry (2005);162(4): pp. 667-675.

37. Herholz K, Herscovitch P, Heiss W-D, "NeuroPET - Positron Emission Tomography in Neuroscience and Clinical Neurology", Berlin: Springer (2004).

38. Herholz K, Salmon E, Perani D, et al., "Discrimination between Alzheimer dementia and controls by automated analysis of multicenter FDG PET", Neuroimage (2002);17: pp. 302-326.

39. Herholz K, Nordberg A, Salmon E, et al., "Impairment of neocortical metabolism predicts progression in Alzheimer's disease”, Dement Geriatr Cogn Disord (1999);10(6): pp. 494-504. 
40. De Leon MJ, Convit A, Wolf OT, et al., "Prediction of cognitive decline in normal elderly subjects with 2-[(18)F]fluoro2-deoxy-D-glucose/poitron-emission tomography (FDG/PET)", Proc Natl Acad Sci USA (2001);98(19): pp. 10966-10971.

41. Chetelat G, Desgranges B, de IS, et al., "Mild cognitive impairment: Can FDG-PET predict who is to rapidly convert to Alzheimer's disease?” Neurology (2003);60(8): pp. 1374-1377.

42. Drzezga A, Lautenschlager N, Siebner $H$, et al., "Cerebral metabolic changes accompanying conversion of mild cognitive impairment into Alzheimer's disease: a PET follow-up study”, Eur J Nucl Med (2003);30(8): pp. 1104-1113.

43. Anchisi D, Borroni B, Franceschi $M$, et al., "Heterogeneity of brain glucose metabolism in mild cognitive impairment and clinical progression to Alzheimer disease” Arch Neurol (2005);62(11): pp. 1728-1733.

44. Jagust $W$, Gitcho A, Sun F, et al., "Brain imaging evidence of preclinical Alzheimer's disease in normal aging", Ann Neurol (2006); 59(4): pp. 673-681.

45. Herholz K, Weisenbach S, Zündorf G, et al., "In vivo study of acetylcholine esterase in basal forebrain, amygdala, and cortex in mild to moderate Alzheimer disease", Neuroimage (2004);21: pp. 136-143.

46. Herholz K, Weisenbach S, Kalbe E, et al., "Cerebral acetylcholine esterase activity in mild cognitive impairment", Neuroreport (2005);16(13): pp. 1431-1434.

47. Mathis CA, Wang Y, Holt DP, et al., "Synthesis and evaluation of 11C-labeled 6-substituted 2-arylbenzothiazoles as amyloid imaging agents”, J Med Chem (2003);46(13): pp. 2740-2754.

48. Klunk WE, Engler $H$, Nordberg A, et al., "Imaging brain amyloid in Alzheimer's disease with Pittsburgh CompoundB”, Ann Neurol (2004);55(3): pp. 306-319.

49. Huddleston DE, Small SA, "Technology Insight: imaging amyloid plaques in the living brain with positron emission tomography and MRI”, Nat Clin Pract Neurol (2005);1(2): pp. 96-105.

50. Mintun MA, LaRossa GN, Sheline YI, et al., "[11C]PIB in a nondemented population: potential antecedent marker of Alzheimer disease”, Neurology (2006);67(3): pp. 446-452.

51. Price JC, Klunk WE, Lopresti BJ, et al., "Kinetic modeling of amyloid binding in humans using PET imaging and Pittsburgh Compound-B”, J Cereb Blood Flow Metab (2005);25(11): pp. 1528-1547.

52. Petersen RC, Morris JC, "Mild cognitive impairment as a clinical entity and treatment target", Arch Neurol (2005);62(7): pp. 1160-1163.

53. Birks J, Flicker L, "Donepezil for mild cognitive impairment", Cochrane Database Syst Rev (2006);3:CD006104.

\section{TOUCH NEUROLOGY}

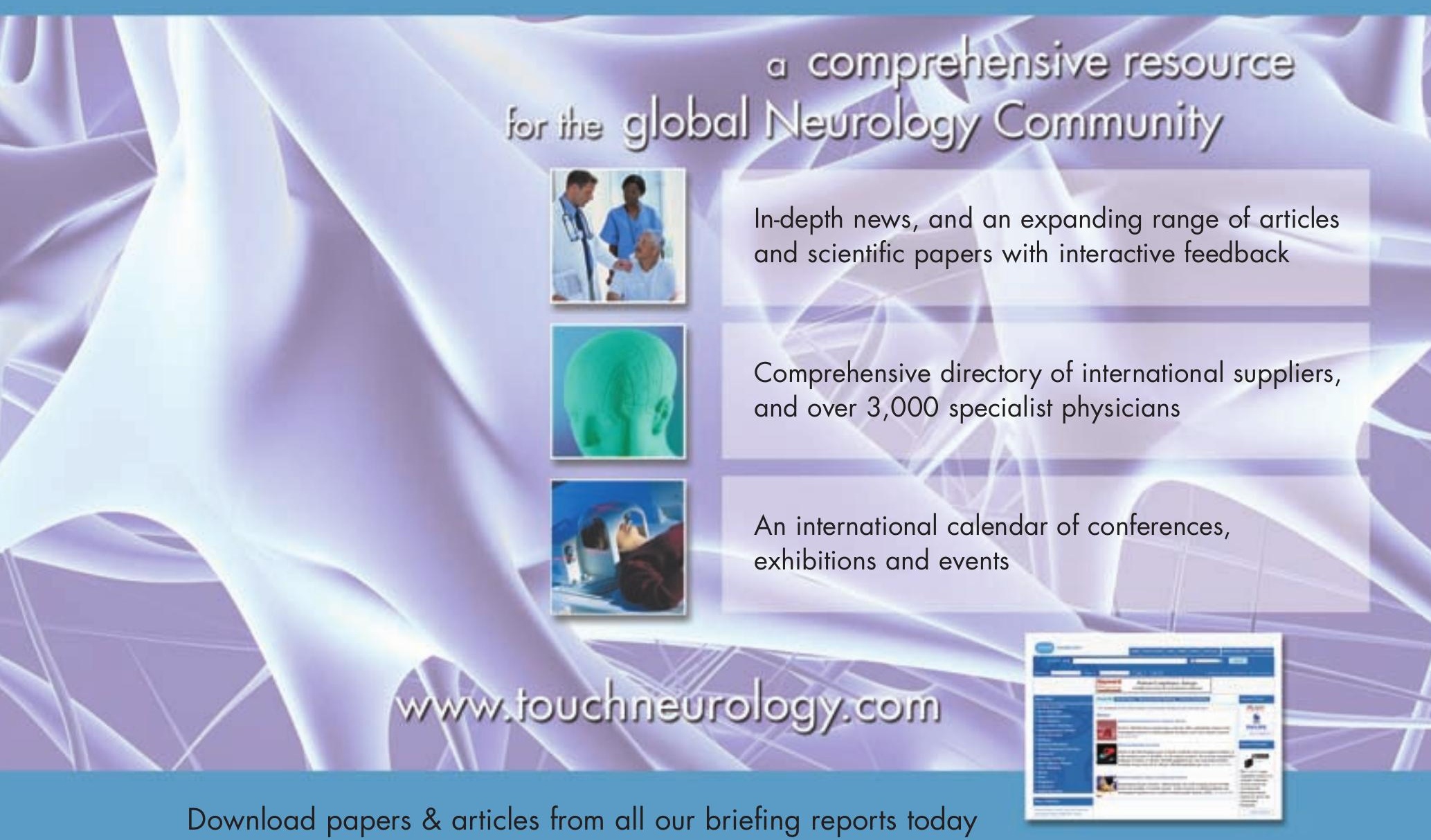




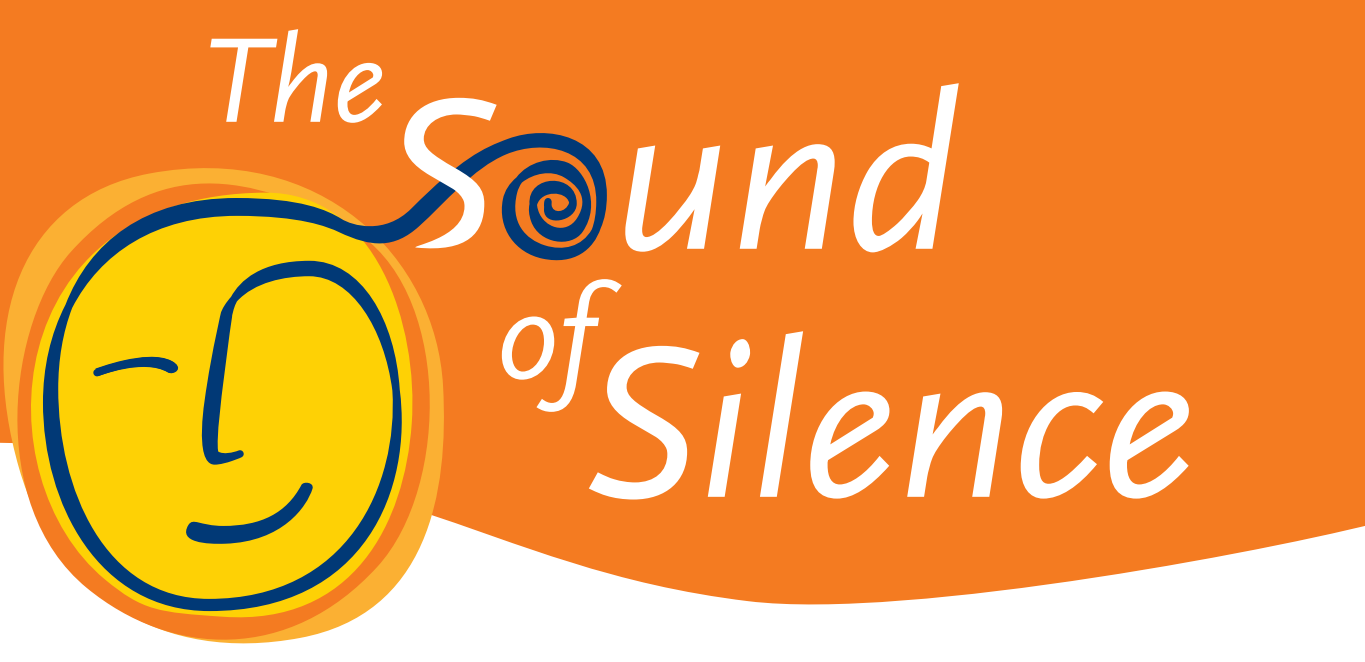

\section{7th Conference}

of Alzheimer Europe

\section{Portugal, Estoril, May 9-12, 2007}

TOPICS:

- Advocacy and Empowerment;

- Specialized research centres;

- Prevalence Rates;

- Training;

- International Projects;

- Quality of care at home;

- How to finance care;

- Respite care;

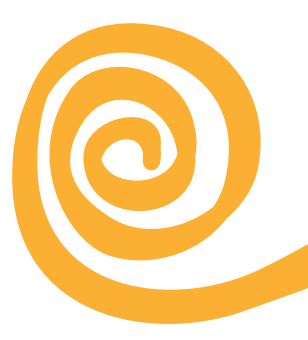

- Non pharmacological interventions;

- Spaces specially built for people

with dementia.

\section{CALL FOR ABSTRACTS}

Abstracts can be submitted via Internet only. The deadline for submission of abstracts is 31 January 2007.

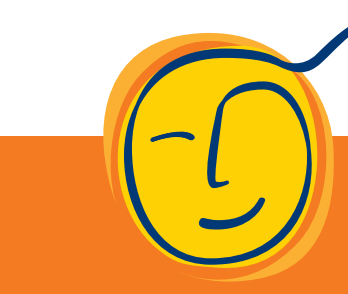

